\title{
AN IN VITRO MODEL OF UROTHELIAL REGENERATION: EFFECTS OF GROWTH FACTORS AND EXTRACELLULAR MATRIX PROTEINS
}

\author{
JOHANNA M. REBEL, WILLEM I. DE BOER, CORNELIA D. THIJSSEN, MARCEL VERMEY, ELLEN C. ZWARTHOFF \\ AND THEODORUS H. VAN DER KWAST \\ Department of Pathology, Erasmus University, P.O. Box 1738, 3000 DR Rotterdam, The Netherlands \\ Received 20 December 1993 \\ Accepted 24 April 1994
}

\begin{abstract}
SUMMARY
Although the cellular turnover of resting urothelium is very low, its regenerative capacity is known to be outstanding. In organotypic mouse urothelial cultures closely mimicking the differentiation and multilayering of normal urothelium, we examined the cell biological mechanisms underlying urothelial regeneration and the specific role of growth factors and several extracellular matrix (ECM) components. Exposure to epidermal growth factor (EGF) and acidic fibroblast growth factor (aFGF) and culture on laminin resulted in enhanced expansion of the urothelium. Microscopy and assessment of proliferative activity revealed that enhanced urothelial expansion due to EGF could be attributed to increased proliferative activity and an increase in cell numbers, whereas aFGFstimulated expansion must be considered the consequence of increased cellularity and migration. Laminin-enhanced urothelial expansion was shown to be the result of spreading of the entire urothelial organotypic culture. This was associated with a considerable decrease in the number of cell layers. A synergistic effect of growth factors and laminin was not found. This organotypic urothelial cell culture model seems to be very useful in studying strategies to improve urothelial regeneration.
\end{abstract}

KEY WORDs-Regeneration, bladder explant, growth factors, extracellular matrix components, migration, proliferation, cell spreading.

\section{INTRODUCTION}

Human bladder cancer is a common cancer in Western society, with considerable morbidity due to its high recurrence rate after local resection of superficial transitional cell carcinomas. ${ }^{1}$ Clinical and experimental data indicate that a substantial proportion of tumour recurrence is the consequence of seeding of tumour cells on traumatized and denuded bladder mucosa. ${ }^{2}$ It can be envisaged that variations in the regeneration rate of traumatized urothelium can influence the incidence of tumour recurrence. The regenerative potential of urothelium after denudation of the bladder mucosa has been studied in several species, including man and mouse, and is known to be outstanding: ${ }^{3,4}$ within $48 \mathrm{~h}$ of the urothelium being stripped, the whole mouse bladder is again covered with urothelium.

In vitro studies on keratinocytes, thyrocytes, and endothelial cells have suggested that growth factors such as epidermal growth factor (EGF), fibroblast growth factor (FGF), and transforming growth factor $\beta$ (TGF $\beta$ ) can influence the migration of these cell types. ${ }^{5-9}$ For the NBT II rat bladder carcinoma cell line, it has been shown that exposure to acid FGF (aFGF) leads to increased migration. ${ }^{10}$

Basement membranes of epithelium, including urothelium, are composed of several extracellular matrix (ECM) components such as laminin, fibronectin (FN), and collagen type IV (COL IV). ${ }^{11,12} \mathrm{ECM}-$ cytoskeletal interactions are also reported to be crucial in the regulation of 
regeneration and wound healing. For example, FN appears to enhance the migration of corneal epithelial cells following wounding ${ }^{13}$ and laminin stimulates the migration of olfactory neuroepithelial cells. ${ }^{14}$ Since data on growth factor and ECM modulation of urothelial regeneration are scarce, we studied these aspects in an in vitro model using organotypic cultures of murine urothelium. For that purpose, explant cultures of adult mouse bladder mucosa on transparent porous membranes, uncoated or coated with ECM, were used as an in vitro model for regenerating urothelium. The culture on transparent membranes allowed daily measurements of the circumference of the explant outgrowths. Previous studies from our laboratory on this culture system had revealed that the outgrowths of the primary murine bladder explants closely mimicked the in vivo situation, since multilayering and maturation to umbrella cells occurred. ${ }^{15,16}$ Our approach contrasts with most previous in vitro studies in which the migration or cell spreading of single cells or cell lines was investigated.

\section{MATERIALS AND METHODS}

\section{Bladder explant culture on porous membranes}

Six- to 8-week-old female C3H/HE mice were killed and the urinary bladder was removed aseptically. The mucosa was stripped from the underlying muscle layer, cut into two pieces, and each half was placed on a transparent porous membrane (Falcon cell-culture insert, cyclopore membrane with a diameter of $25 \mathrm{~mm}$; pore size $0.45 \mu \mathrm{m})$. The lamina propria of the explant was always in contact with the membrane, as described previously. ${ }^{15}$ The medium of the porous membrane cultures was replaced every other day with standard medium [a 1:1 mixture of Dulbecco's modified Eagle's medium (DMEM) and Ham's F10 medium with 10 per cent heat-inactivated fetal calf serum (FCS) and supplement as described previously ${ }^{15}$ ]. In some experiments, growth factors were added to the standard medium beginning at day 4 (as indicated in the text). The growth factors used were aFGF, $20 \mathrm{ng} / \mathrm{ml}$, obtained from Boehringer Mannheim (Almere, The Netherlands); and $\mathrm{EGF}, 20 \mathrm{ng} / \mathrm{ml}$, and $\mathrm{TGF} \beta, 1 \mathrm{ng} / \mathrm{ml}$, obtained from Sigma (St. Louis, U.S.A.). This growth factor-supplemented medium was changed every other day.

The circumference of the bladder outgrowth was monitored daily through a light microscope. From these overviews the expansion of the outgrowth was determined. The surface area as determined in $\mathrm{mm}^{2}$ was related to the total surface of the porous membrane. When the outgrowth covered the whole membrane, 100 per cent outgrowth was reached. Only explant cultures exceeding an outgrowth of 8.5 per cent on day 4 were included in the study in order to obtain only actively growing cultures.

Two hours before termination of the culture, $40 \mu \mathrm{g} / \mathrm{ml}$ bromodeoxyuridine (BrdU) was added.

\section{Culture substrates}

FN and laminin (Sigma, St. Louis, U.S.A.) were diluted in phosphate-buffered saline (PBS) to a concentration of $25 \mu \mathrm{g} / \mathrm{ml}$. COL IV (kindly donated by Dr J. P. M. Cleutjens of the Department of Pathology, University of Limburg, The Netherlands) and collagen type I (COL I) (Vitrinogen 100; ICN Laboratories, Amsterdam, The Netherlands) were diluted in Ham's F10 to a concentration of $25 \mu \mathrm{g} / \mathrm{ml}$. Porous membranes were covered with $0.5 \mathrm{ml}$ of a solution containing one of the ECM proteins and incubated overnight at $37^{\circ} \mathrm{C}$ in a humidified atmosphere. Coated membranes were then incubated with $2.5 \mathrm{mg}$ of bovine serum albumin (BSA) for $30 \mathrm{~min}$ at $37^{\circ} \mathrm{C}$ to block non-specific binding sites on the membrane. Explants on BSA-coated membranes were regarded as negative controls, since BSA is not an adhesion molecule. Membranes were washed with $\mathrm{H}_{2} \mathrm{O}$ and dried overnight. The next day, the bladder explants were placed on the membrane.

\section{$\left[^{3} H\right]$ Thymidine incorporation}

When the primary bladder culture covered an area of 60-65 per cent, the standard medium was replaced by serum-free DMEM with supplements containing $20 \mu \mathrm{Ci}$ of $\left[{ }^{3} \mathrm{H}\right]$ thymidine $/ \mathrm{ml}(1.25 \mathrm{ml} /$ membrane), in which the urothelium was cultured for another $2 \mathrm{~h}$. Subsequently, the culture was rinsed with PBS with an excess of non-labelled thymidine. The incorporated radioactivity was counted in Ultima Gold (Packard, Groningen, The Netherlands) using an $\alpha, \beta$-scintillation analyser (as described previously ${ }^{16}$ ). Before incorporated $\left[{ }^{3} \mathrm{H}\right]$ thymidine was counted, the membranes were immunohistochemically stained and counterstained with haematoxylin. To preserve an adequate morphology, trichloroacetic acid (TCA) treatment of the membranes was omitted. Control 
experiments revealed no differences in the $\left[{ }^{3} \mathrm{H}\right]$ thymidine incorporation values between membranes incubated and washed with 15 per cent TCA and the corresponding untreated membranes.

\section{Reagents for immunohistochemistry}

Monoclonal antibody RGE 53 (specific for cytokeratin 18) was obtained from Eurodiagnostica (Apeldoorn, The Netherlands). RGE 53 was employed to visualize the more mature urothelial cells. With this staining, cells with a typical morphology of umbrella cells can be distinguished more easily. The monoclonal antibody against BrdU was obtained from Dr Ramaekers (University of Maastricht, The Netherlands). For BrdU staining, the ethanol-fixed membranes were pretreated with $1 \mathrm{M} \mathrm{HCl}$ following the procedure described in ref. 17. The membranes were incubated with the primary antibody overnight at $4^{\circ} \mathrm{C}$. Subsequently, an indirect conjugated peroxidase method was applied. A goat anti-mouse immunoglobulin (Ig)-peroxidase conjugate obtained from DAKO (Glostrup, Denmark) was used. Diaminobenzidine (DAB) was used as a chromogen. The DAB solution was prepared by dissolving $75 \mathrm{mg}$ of DAB tetrahydrochloride (Fluka, Oud-Beyerland, The Netherlands) in $100 \mathrm{ml}$ of PBS, and $50 \mu 1$ of 30 per cent hydrogen peroxidase was added as a substrate. For visualization of bound antibody, the membranes were incubated for $7 \mathrm{~min}$ with DAB solution and the sections were washed in distilled water. All membranes were counterstained with Mayer's haematoxylin.

To evaluate the number of immunostained urothelial cell layers more accurately, strokes of the immunostained porous membranes covered with urothelial cells were dipped in 5 per cent gelatin, dried overnight in air, and embedded in paraffin. Cross-sections $(5 \mu \mathrm{m})$ perpendicular to the surface were made. The remaining parts of the membranes were dehydrated in alcohol and embedded in Euparal (Chroma-Gesellschaft Stuttgart, Germany).

\section{Quantification of cell density and cell spreading}

To quantify the cell density of the urothelium, the number of nuclei was counted in 14 random areas of $0.15 \mathrm{~mm}^{2}$ in the outgrowth explant cultures used for $\left[{ }^{3} \mathrm{H}\right]$ thymidine incorporation. At this time, the bladder outgrowth covered about 60-65 per cent of the membrane. The average \pm SEM of three independent experiments with two samples each was taken.

In cultures covering approximately 100 per cent of the supportive membrane, the degree of cell spreading was evaluated by counting the number of basal nuclei on cross-sections over a distance of $5 \mathrm{~mm}$. In each membrane, eight random positions at the peripheral part of the culture were chosen for evaluation.

\section{RESULTS}

\section{Modulation of expansion of the primary bladder outgrowth}

In explant cultures kept in standard medium containing 10 per cent FCS (control outgrowth), the urothelium immediately began to expand as a sheet of epithelial cells after attachment of the explants to the cyclopore membrane. The edges of the outgrowth of primary urothelium were well demarcated throughout the experimental period. This permitted easy measurement of the surface covered by the expanding urothelium. On day 4 , the urothelial outgrowth covered more than 8.5 per cent of the membrane in 80 per cent of the cases. The whole membrane was covered in approximately 22 days (100 per cent urothelial outgrowth). Addition of EGF and aFGF to the standard medium containing 10 per cent FCS led to an increase in the expansion rate from day 7 onwards as compared with the controls $(P \leq 0 \cdot 01)$ (Fig. 1). Addition of TGF $\beta$ resulted in significant inhibition of the expansion from day 7 onwards.

The expansion rate of primary urothelium was also examined on membranes coated with different ECM proteins. No growth factors were added to the standard medium. In 95 per cent of the cultures grown on ECM-coated membranes, the outgrowth was over 8.5 per cent on day 4 . The attachment percentage ( 40 per cent) and the expansion rate of explants on BSAcoated membranes were significantly smaller than on uncoated membranes (Fig. 2). No significant difference in the expansion rate was observed between urothelial cultures grown on COL IV-, FN-, or COL I-coated supportive membranes and uncoated membranes (Fig. 2). It is probable that constituents of FCS provide an adhesive substrate allowing the expansion of urothelial cells on uncoated membranes. However, the proportion of successfully attached explants was higher 


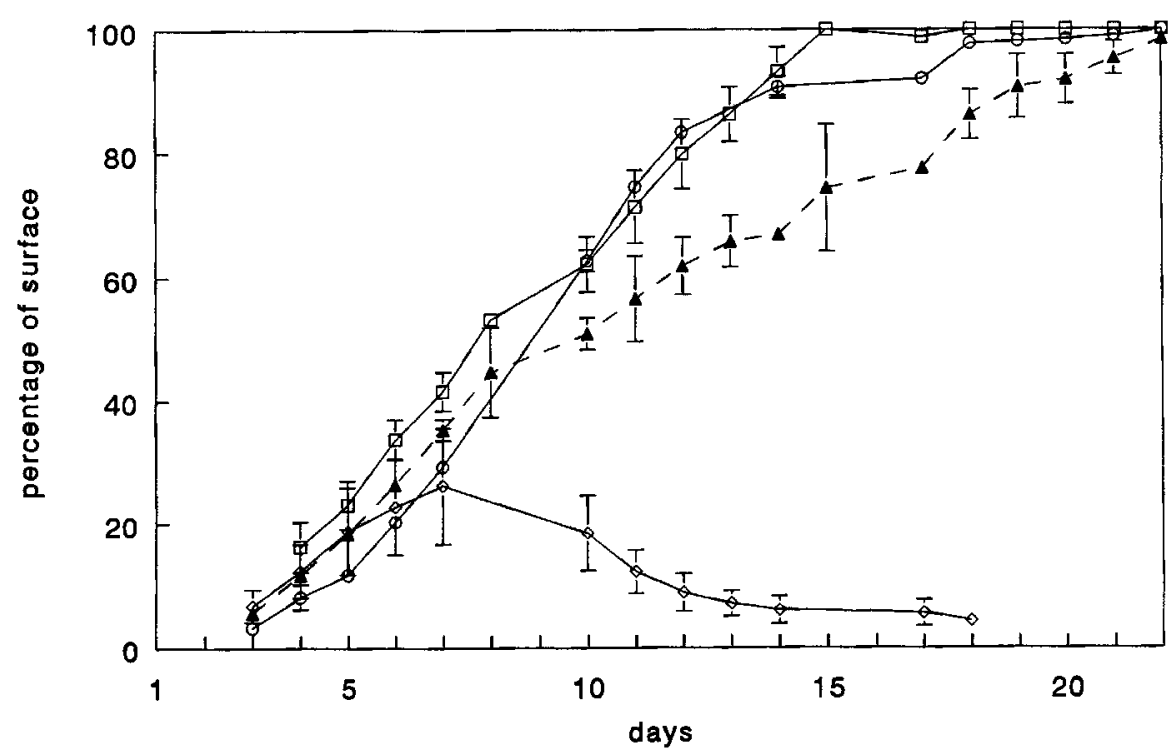

Fig. 1-Influence of growth factors on the expansion rate of explant cultures. $O$, EGF; $\square$, aFGF; $\diamond$, TGF $\beta ; \Delta$, control. Data are expressed as the mean \pm SEM of three independent experiments with three samples each

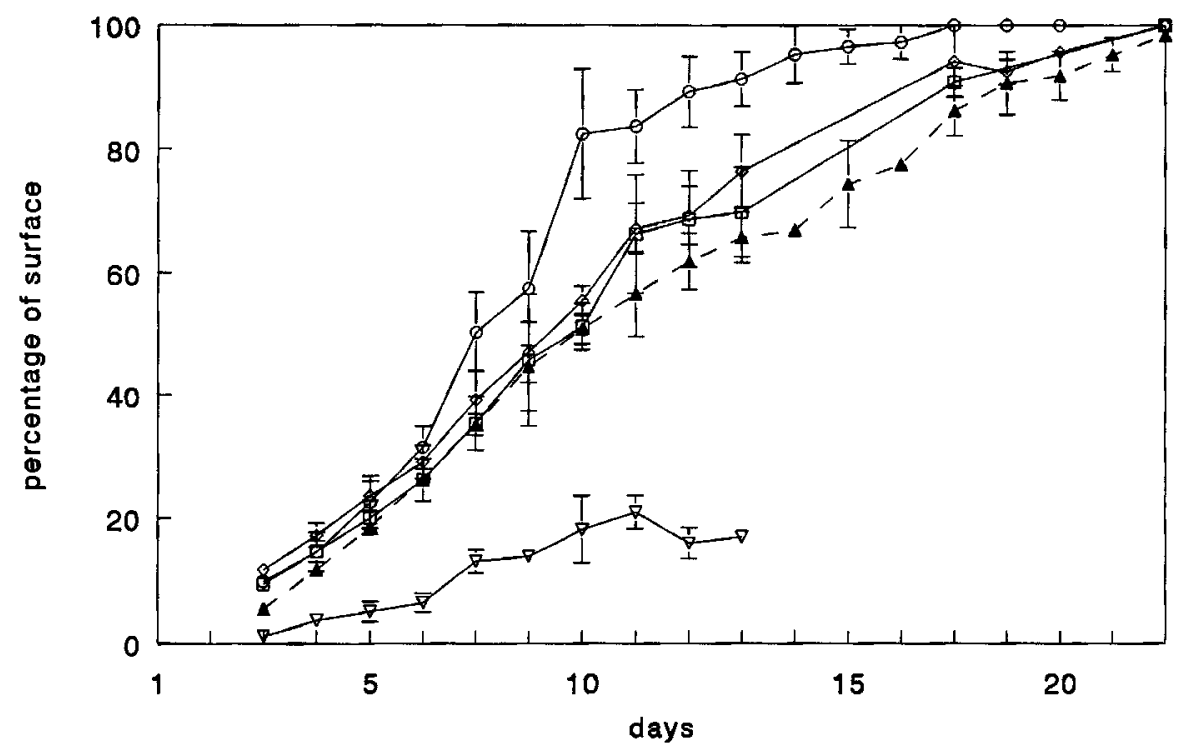

Fig. 2-Influence of ECM on the expansion rate of explant cultures. $\diamond, \mathrm{FN} ; \bigcirc$, laminin; $\Lambda$, control; $\nabla, \mathrm{BSA} ; \square$, COL IV. Mean \pm SEM was calculated as explained in the legend of Fig. 1

on the ECM-coated membranes than on the uncoated membranes (i.e., 95 per cent vs. 80 per cent). The expansion of the urothelium cultured on laminin increased from day 7 onwards compared with the other cultures $(P \leq 0 \cdot 01)$.
Figure 3 illustrates the outgrowth of urothelial cultures grown on FN-, laminin-, COL IV-, or COL I-coated membranes in the presence or absence of EGF. Addition of EGF led to an increased expansion rate of urothelium on FN, 


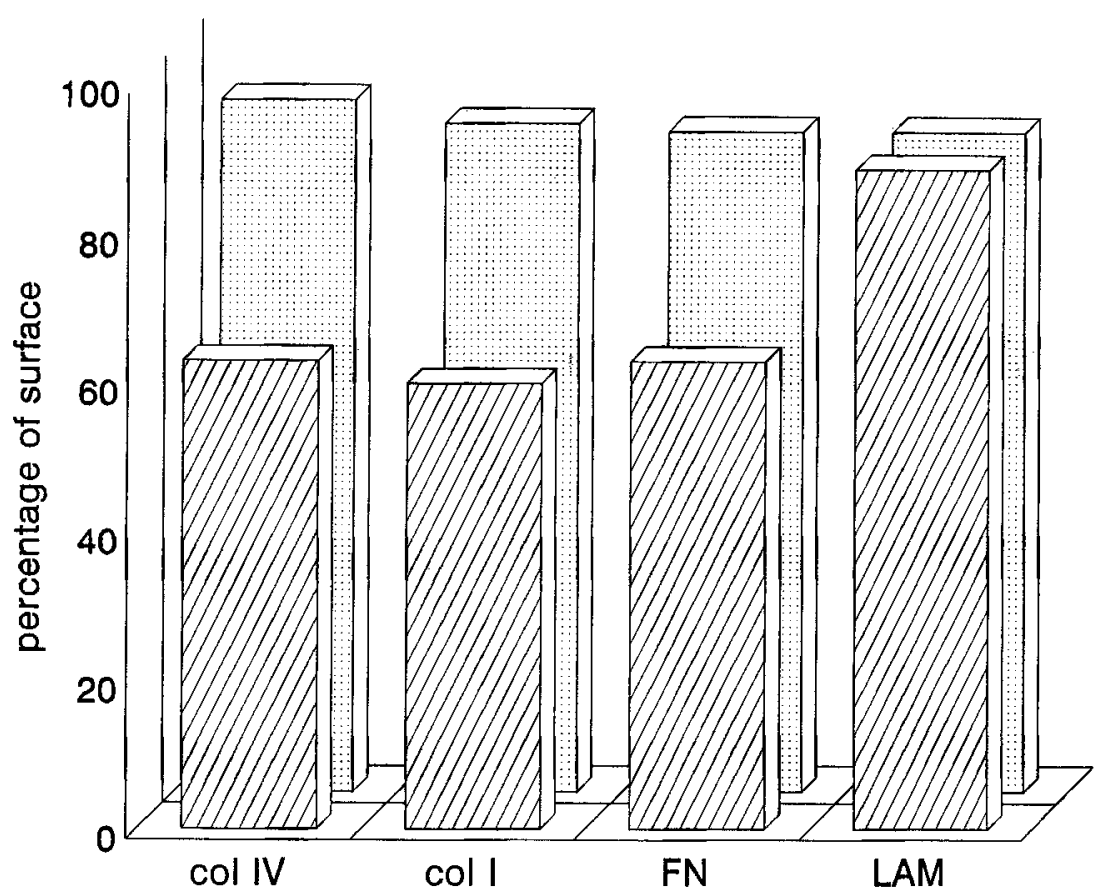

Fig. 3-Influence of EGF on the expansion rate of explant cultures grown on ECM. Cultured for 11 days. Hatched bars represent explants cultured in the absence of EGF and dotted bars represent explants cultured in the presence of EGF

COL IV, and COL I, but did not influence the expansion rate of urothelium grown on laminin.

\section{Modulation of multilayering and cellularity in the primary bladder outgrowth}

After termination of the cultures, immunohistochemistry with antibody RGE 53 was performed in order to visualize maturation to umbrella cells. Cells with the typical morphology of umbrella cells were identified in control explant cultures, in cultures exposed to aFGF and TGF $\beta$, and in urothelial outgrowths on all coated membranes without addition of growth factors. No RGE 53-positive cells with the typical morphology of umbrella cells were found in EGF-treated cultures. Furthermore, the exposure of urothelium on ECM-coated membranes to EGF was associated with the disappearance of RGE 53-positive cells with the morphology of umbrella cells (Figs $4 a-4 c$ ).

Cross-sections of immunostained membranes (Figs 5a-5d) revealed that at near-confluence, EGF-treated cultures had an increased thickness of 3-5 cell layers, as opposed to 2-3 cell layers in untreated cultures. The cellularity increased from $179 \pm 35$ cells $/ 0 \cdot 15 \mathrm{~mm}^{2}$ in untreated cultures to $414 \pm 14$ cells $/ 0 \cdot 15 \mathrm{~mm}^{2}$ in EGF-treated cultures. In aFGF-treated cultures, the cellularity also increased to $280 \pm 52$ cells and the cultures consisted of 2-3 cell layers with an upper layer of flattened RGE 53-positive umbrella cells. The TGF $\beta$-treated culture consisted of one single cell layer of very large RGE 53-positive cells. Its cellularity decreased to $67 \pm 1$ cell $/ 0 \cdot 15 \mathrm{~mm}^{2}$.

In cross-sections of the urothelial outgrowths on COL I-, COL IV-, or FN-coated membranes (Figs $5 \mathrm{e}-5 \mathrm{~h}), 2-3$ cell layers were observed. The top layer of these cultures consisted of flattened RGE 53positive cells with the morphology of umbrella cells. Urothelium on laminin-coated membranes consisted of one cell layer of large flattened RGE 53-positive cells with a remarkably low nuclear density in the basal cell layer (Table I).

Cross-sections of immunostained coated membranes showed that in the presence of EGF the number of cell layers and the nuclear density of the basal cell layer (Table I) were increased in all cultures irrespective of the coating (Figs $5 \mathrm{i}$ and $5 \mathrm{j}$ ). 

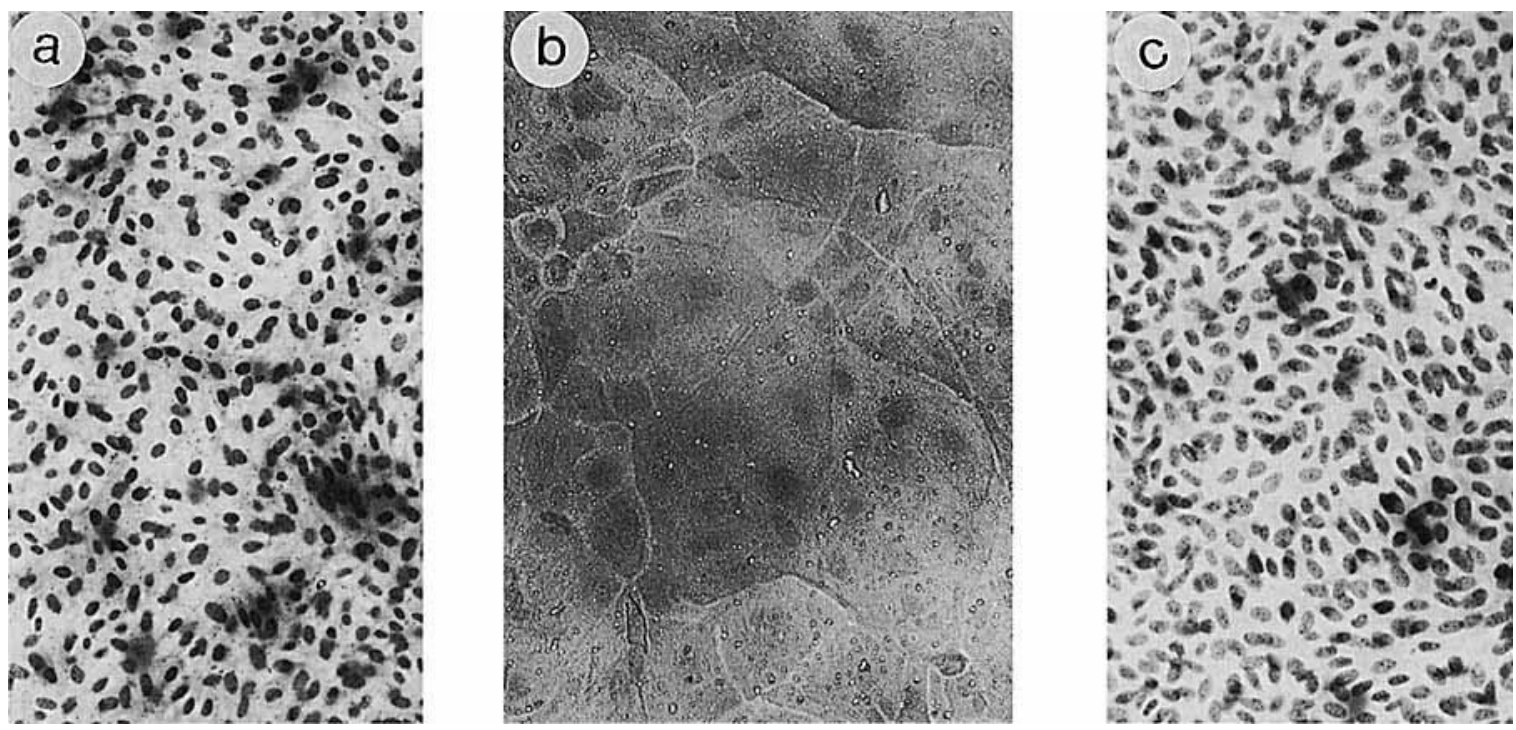

Fig. 4 Overviews of the bladder explant after 20 days of culture. All cultures were immunohistologically stained with RGE 53, an antibody against cytokeratin 18, and counterstained with haematoxylin. (a) Overview of an EGF-treated culture. Note the absence of RGE 53-positive cells. (b) Overview of a bladder explant cultured on COL IV. The cells have the typical morphological appearance of umbrella cells. (c) A bladder explant cultured on COL IV with addition of EGF. Note the absence of RGE 53-positive cells

\section{Modulation of the proliferation of the primary bladder outgrowth}

Table I shows that an increase in proliferative activity, as measured by $\left[{ }^{3} \mathrm{H}\right]$ thymidine incorporation at the time that the culture reached $60-65$ per cent outgrowth, was observed only in cultures exposed to EGF. Direct visualization of prolifer- ating cells by immunostaining with anti-BrdU antibody revealed that these cells were evenly dispersed over the membrane. In contrast, 50 per cent of the aFGF-exposed cultures lacked these BrdU-positive cells in the periphery of the culture (data not shown).

Cultures on ECM-coated membranes generally had a lower proliferative activity than the control.

Table I-Proliferation, spreading of basal cells, and number of cell layers in organotypic urothelial cell cultures

\begin{tabular}{lccc}
\hline & \multicolumn{3}{c}{ No. of } \\
& $\begin{array}{c}\text { [ncorporation, } \\
\text { DPM } \pm \text { SD }\end{array}$ & $\begin{array}{c}\text { nuclei in the } \\
\text { basal cell } \\
\text { layer } \pm \text { SEM }\end{array}$ & $\begin{array}{c}\text { No. of } \\
\text { cell layers }\end{array}$ \\
\hline Control & $75893 \pm 10550$ & $7 \cdot 7 \pm 0 \cdot 2$ & $2-3$ \\
EGF & $311047 \pm 3790$ & $15 \cdot 3 \pm 0 \cdot 6$ & $3-5$ \\
aFGF & $72154 \pm 9495$ & $9 \cdot 3 \pm 0 \cdot 8$ & $2-3$ \\
COL IV & $35344 \pm 18602$ & $9 \cdot 3 \pm 0 \cdot 7$ & $2-3$ \\
COL I & $39448 \pm 15102$ & $7 \cdot 9 \pm 0 \cdot 8$ & $2-3$ \\
FN & $32577 \pm 14187$ & $7 \cdot 3 \pm 0 \cdot 6$ & $2-3$ \\
Laminin & $20007 \pm 11776$ & $3 \cdot 7 \pm 0 \cdot 8$ & 1 \\
COL IV + EGF & $179624 \pm 36791$ & $13 \cdot 1 \pm 2 \cdot 8$ & $3-4$ \\
COL I+EGF & $139756 \pm 3788$ & $13 \cdot 4 \pm 2 \cdot 6$ & $3-4$ \\
FN+EGF & $103313 \pm 21266$ & $13 \cdot 8 \pm 3 \cdot 1$ & $3-4$ \\
Laminin + EGF & $130460 \pm 24255$ & $15 \cdot 1 \pm 2 \cdot 4$ & $3-4$ \\
& & & \\
\hline
\end{tabular}



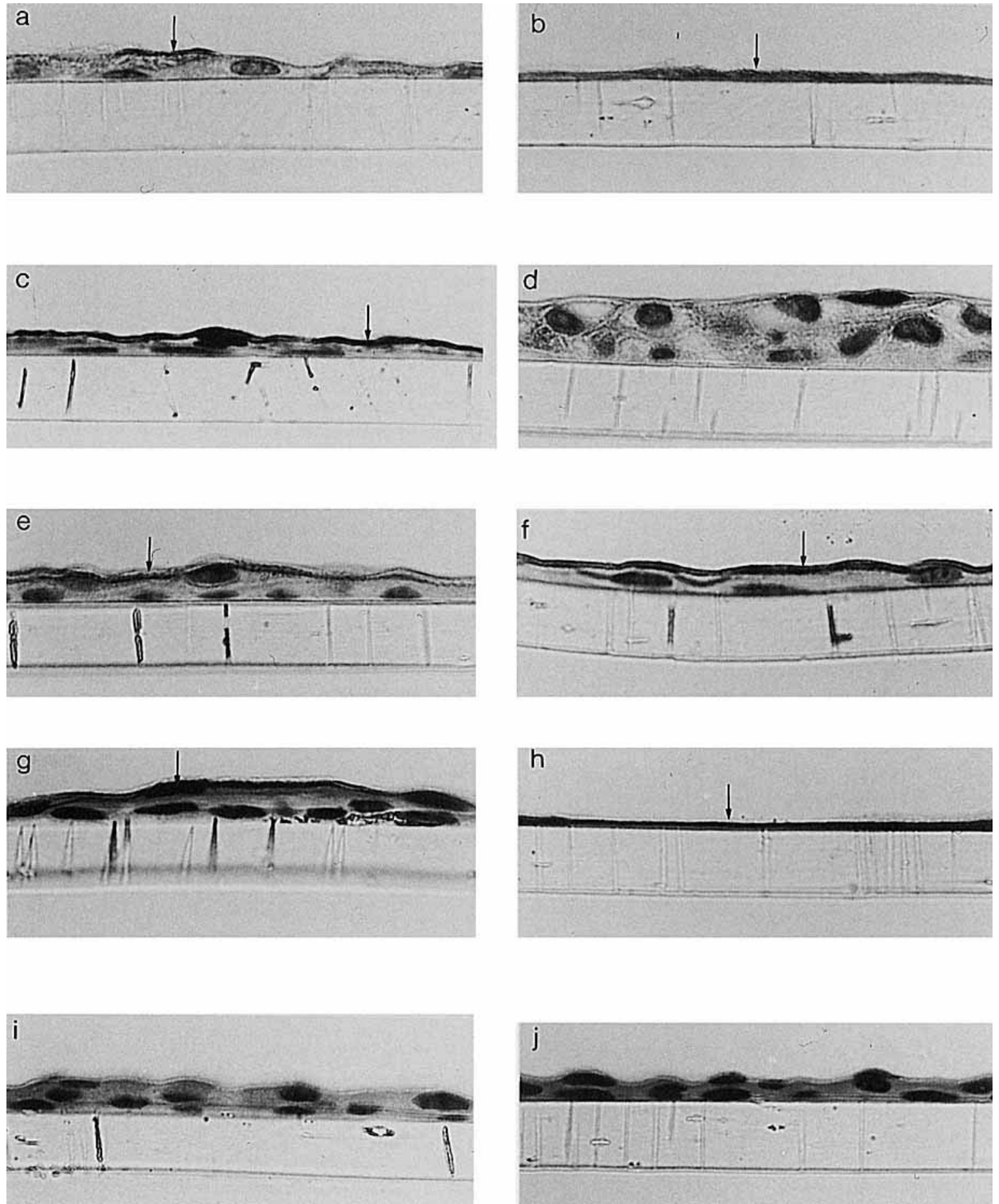

Fig. 5-Cross-sections of different urothelial cultures $(\times 1000)$. Supportive membranes are immediately below the urothelium. Arrows indicate the RGE 53-positive cells. (a) Control; (b) TGF $\beta$ culture; (c) aFGF culture; (d) EGF culture; (e) grown on COL I; (f) grown on FN; (g) grown on COL IV; (h) grown on laminin; (i) grown on COL IV with addition of EGF; (j) grown on laminin with addition of EGF 
No difference in $\left.{ }^{3} \mathrm{H}\right]$ thymidine incorporation was found between the cultures when grown on different ECM-coated membranes. Direct visualization of BrdU-containing urothelial cells demonstrated proliferating cells in a peripheral concentric zone in 75 per cent of the cultures.

Cultures grown on ECM components in the presence of EGF demonstrated an increase in $\left[{ }^{3} \mathrm{H}\right]$ thymidine incorporation compared with the primary urothelium grown on the ECM-coated membranes in the absence of EGF (Table I).

\section{DISCUSSION}

The high regenerative capacity of the bladder urothelium after acute damage is remarkable in view of the slow turnover of the normal transitional epithelium. Several mechanisms may account for the rapid re-epithelialization of the bladder surface. These could include extension of the surfaces of residual cells, migration of cells out of the urethra and ureteric orifices, and an increase in the proliferation of the residual urothelial cells. ${ }^{18}$

In this study we present evidence that each of these mechanisms was operating in our organotypic regeneration model, either separately or in combination. In this organotypic culture system we studied the effects of growth factors or ECM components on the expansion of a cohesive sheet of primary urothelial cells, instead of the effect of these factors on individual cells, as most studies do. We demonstrated an increase in the expansion rate of mouse bladder explants cultured in the presence of either EGF or aFGF, and when grown on laminin. Strikingly, the observed increase in expansion of the urothelium was accompanied by different morphological and functional features, dependent on the culture conditions applied.

EGF stimulation of the urothelial expansion rate was associated with an increased number of cell layers and a higher cellular density, as well as a loss of maturation into umbrella cells. The effect of EGF on expansion may thus be attributed to the observed strong increase in proliferative capacity. Previous studies on mouse and human epithelium also demonstrated an EGF-mediated stimulation of proliferation. ${ }^{19-21}$ Similarly, Schultz et al. ${ }^{22}$ showed that regeneration of corneal epithelial cells in vivo is regulated by EGF.

In urothelial cultures grown on laminin-coated membranes, the proliferative activity was decreased and at the peripheral parts of the culture the urothelium consisted of only one flattened cell layer, with low nuclear density. The latter feature indicates enhanced cell spreading of this cohesive sheet of cells. Laminin-induced spreading of dispersed individual cells has been described for other cell types, ${ }^{23-25}$ but as yet not for organotypic cultures. It is most likely that the laminin-induced increase in urothelial expansion is due to this spreading of the urothelial cells.

To explain the mechanism by which aFGF induced an increased expansion rate is more complex. Addition of aFGF increased the cellularity of the urothelial culture, but at 60 per cent of confluence the proliferation rate of the aFGF-stimulated cultures was similar to controls. Furthermore, at the peripheral edge of the aFGF-stimulated cultures, proliferating (BrdU-positive) cells were largely absent. This suggests that proliferation does not greatly contribute to the aFGF-induced urothelial expansion. More likely, migration rather than stretching or proliferation of the urothelial cells contributes to the observed aFGF-enhanced expansion. This hypothesis is in line with the work of Valles $e t$ al. $^{26}$ in which the authors showed that aFGF can serve as a migration factor in a rat bladder carcinoma cell line. Similarly, migration of urothelial cells may be involved in the expansion of explants cultured on COL I, COL IV, or FN. In these cultures, proliferative activity is decreased, whereas the number of cell layers and the expansion rate remain equal to that of the cultures on uncoated membranes. Migration of epithelial cells on COL IV, COL I, and FN has also been found in other studies, ${ }^{27,28}$ but as yet not in organotypic urothelial cultures. The enhanced migration of ECM-coated membranes of the urothelial cells is probably due to an interaction of the ECM with ECM-specific integrins. ${ }^{29}$ Unfortunately, we were not able to detect $a 3, a 5, a 6, \beta 1$, or $\beta 4$ subunits using immunohistochemistry.

The negative effect of TGF $\beta$ on the expansion rate of the urothelium is probably due to the induction of maturation and apoptosis in urothelial cells. ${ }^{30,31}$

Another question addressed by this study was whether growth factors can act synergistically with the ECM in order to enhance expansion, which was tested by culturing the urothelium on COL I, COL IV, FN, or laminin and adding EGF to the culture. Exposure to EGF led to greater urothelial expansion of COL I-, COL IV-, and FN-coated membranes, but not on laminin-coated membranes. Apparently, the mechanism of 
(laminin-mediated) cell spreading is not synergistic with the expanding effect of EGF-mediated proliferation. Indeed, the high nuclear density of basal cells in EGF-treated cultures on laminin-coated membranes demonstrated that the lamininmediated cell spreading is inhibited by exposure to EGF. EGF may have changed the integrin expression pattern in such a way that the lamininmediated cellular spreading is diminished. On the other hand, ECM coating of membranes reduced the EGF-associated increase in the number of cell layers, but not the increased level of $\left[{ }^{3} \mathrm{H}\right]$ thymidine incorporation.

In conclusion, this in vitro mouse urothelium regeneration model has permitted the identification of separate factors which selectively mediate the different mechanisms underlying the regeneration of urothelium in vivo. We failed to show a synergism between the different mechanisms of regeneration. Future studies should indicate whether these factors may also operate in vivo, during the regeneration of normal urothelium after therapeutic denudation of the urothelium.

\section{ACKNOWLEDGEMENTS}

We wish to thank Mr F. L. van der Panne from our department for the photography. This study was supported by the Dutch Cancer Foundation (IKR 90-17).

\section{REFERENCES}

1. Raghavan D, Shipley WU, Garnick MB, Russell PJ, Richie IP Biology and management of bladder cancer. N Engl J Med 1990; 322: $1129-1138$.

2. Hinman FJ. Recurrence of bladder tumors by surgical implantation. J Urol 1956; 75: 695-696.

3. Liang DFS, Goss RJ. Regeneration of the bladder after subtotal cystectomy in rats. J Urol 1963; 89: 427-430.

4. Wishnow KI, Johnson DE, Grignon DJ, Cromeens DM, Ayala AG. Regeneration of the canine urinary bladder mucosa after complete surgical denudation. J Urol 1989; 141: 1467-1479.

5. Nickoloff BJ, Mitra RS, Riser BL, Dixit VM, Varani J. Modulation of keratinocyte motility. Am $J$ Pathol 1988; 132: 543-551.

6. Gherardi E, Gray J, Stoker M, Perryman M, Furlong R. Purification of scatter factor, a fibroblast derived basic protein that modulates epithelial interactions and movement. Proc Natl Acad Sci USA 1989; 86: $5844-5848$.

7. Schultz G, Rotatori DS, Clark W. EGF and TGFa in wound healing and repair. J Cell Biochem 1991; 45: 346-352.

8. Westermark K, Nilsson M, Westermark B. Thyrocyte migration and histiotypic follicle regeneration are promoted by epidermal growth factor in primary culture of thyroid follicles in collagen gel. Endocrinology 1991; 129: 2180-2186.

9. Kartha S, Toback FG. Adenine nucleotides stimulate migration in wounded cultures of kidney epithelial cells. $J$ Clin Invest 1992; 90: 288-292.

10. Tucker GC, Delouveé A, Jouanneau J, Gavrilic GM, Vallés AM, Thiery JP. Amplification of invasiveness in organotypic cultures after NBT II rat bladder carcinoma stimulation with in vitro scattering factors. Invasion Metastasis 1991; 1: 297-309.
11. Gardiner RA, Seymour GJ, Lavin MF, Strutton GM, Gemmel E, Hazan G. Immunohistochemical analysis of the human bladder. $\mathrm{Br}$ $J$ Urol 1986; 58: 19-25.

12. Conn IG, Crocker J, Wallace DMA, Hughes MA, Hilton CJ. Basement membranes in urothelial carcinoma. Br J Urol 1987; 69: 536-542.

13. Nishida T, Nakamura M, Mishima H, Otori T. Differential modes of action of fibronectin and epidermal growth factor on rabbit corneal epithelial migration. J Cell Physiol 1990; 145: 549-554.

14. Calof AL, Lander AD. Relationship between neuronal migration and cell-substratum adhesion: laminin and merosin promote olfactory neuronal migration but are anti-adhesive. J Cell Biol 1991; 115: 779-794.

15. Rebel JMJ, De Boer WI, Thijssen CDEM, Vermey M, Zwarthoff EC, Van Der Kwast ThH. An in vitro model of intra-epithelial expansion of transformed urothelial cells. Int $J$ Cancer 1993; 54: $846-850$

16. De Boer WI, Rebel JMJ, Vermey M, Thijssen CDEM, Van Der Kwast ThH. Multiparameter analysis of primary epithelial cultures grown on cyclopore membranes. J Histochem Cytochem 1994; 42 $277-282$

17. Schutte B, Reynders MMJ, Van Assche CLMVJ, Hupperets PSGJ, Bosman FT, Blijham GH. Studies with anti-bromodeoxyuridine antibodies. Cytometry 1987; 8: 372-376.

18. Hicks RM. The mammalian urinary bladder: an accommodating organ. Biol Rev 1975; 50: 215-246.

19. Dubeau L, Jones PA. Growth of normal and neoplastic urothelium and response to epidermal growth factor in a defined serum-free medium. Cancer Res 1987; 47: 2107-2112.

20. De Boer WI, Rebel JMJ, Foekens JA, Vermey M, Van Der Kwast ThH. Characterisation of mouse urothelial cell lines in different phases of transitional-cell carcinogenesis. Int $J$ Cancer 1993; 54: 1022-1027.

21. Pusztai L, Lewis CE, Lorenzen J, McGee J. Growth factors: regulation of normal and neoplastic growth. $J$ Pathol 1993; 169: 191-201.

22. Schultz G, Chegini N, Grant M, Khaw P, Mackay S. Effects of growth factors on corneal wound healing. Acta Ophthalmol 1992; 70: 60-66.

23. Deutzmann R, Aumailley M, Wiedemann GH, Pynsny W, Timpl R, Edgar D. Cell adhesion, spreading and neurite stimulation by laminin fragment E8 depends on maintenance of secondary and tertiary structure in its rod and globular domain. Eur $J$ Biochem 1990; 191: 513-522.

24. Massia SP, Rao SS, Hubbel JA. Covalently immobilized laminin peptide Tyr-Ile-Gly-Ser-Arg (YIGSR) supports cell spreading and co-localization of the 67-kilodalton laminin receptor with $a$-actinin and vinculin. $J$ Biol Chem 1993; 268: 8053-8059.

25. Engvall E. Laminin variants: why, where and when? Kidney Int 1993; 43: 2-6.

26. Valles AM, Boyer B, Badet J, Tucker GC, Barritault D, Thiery JP. Acidic fibroblast growth factor is a modulator of epithelial plasticity in a rat bladder carcinoma cell line. Proc Natl Acad Sci USA 1990; 87: 1124-1128.

27. Nishida T, Nakagawa S, Awata T, Ohashi Y, Watanabe K, Manabe R. Fibronectin promotes epithelial migration of cultured rabbit cornia in situ. J Cell Biol 1983; 97: 1653-1657.

28. Moore R, Madri J, Carison S, Madara JL. Collagens facilitate epithelial migration in restitution of native guinea pig intestinal epithelium. Gastroenterology 1992; 102: 119-130.

29. Kurpakus MA, Quaranta V, Jones JCR. Surface relocation of alpha 6 beta 4 integrins and assembly of hemidesmosomes in an in vitro model of wound healing. $J$ Cell Biol 1991; 115: 1737-1750.

30. Rotello RJ, Lieberman RC, Purchio AF, Gerschenson LE. Coordinated regulation of apoptosis and cell proliferation by transforming growth factor beta 1 in cultured uterine epithelial cells. Proc Natl Acad Sci USA 1991; 88: 3412-3415.

31. De Boer WI, Rebel JMJ, Vermey M, De Jong AAW, Van der Kwast ThH. Characterization of distinct functions for growth factors in murine transitional epithelial cells in primary organotypic culture. Exp Cell Res (in press) 